\title{
PENERAPAN TAX PLANNING ATAS WITHHOLDING TAX SYSTEM TERHADAP PAJAK PENGHASILAN BADAN PADA PT. CAT
}

\author{
Nurwati $^{1 *}$, Syaiful Anwar ${ }^{2}$ \\ Institut Teknologi dan Bisnis Ahmad Dahlan \\ email: watisyam77@gmail.com
}

\begin{abstract}
This study aims to analyze the Application of Tax Planning on Withholding Tax to Corporate Income Tax at PT. CAT in accordance with applicable Tax Regulations. The research method used is descriptive qualitative method. The results showed that PT. CAT has not been optimal in carrying out Tax Planning for the Withholding Tax System for Corporate Income Tax. Because it was found inefficiency to the income tax Article 21 paid as much as Rp. 53,261,874. PT. CAT has cut and collected PPh article 23 and article 4 paragraph (2) in accordance with applicable taxation provisions. Based on published data, there is no potential for Income Tax Article 23 and Article 4 paragraph (2) to be deducted / paid during 2018.
\end{abstract}

Keyword: Tax Planning, PPh Badan, dan Withholding Tax System

\section{PENDAHULUAN}

Pembangunan nasional dilaksanakan untuk mengintegrasikan perekonomian dari daerah ke pusat begitupun sebaliknya, melalui program pemerintah saat ini yaitu Nawa Cita atau Nawacita yang diambil dari bahasa sansekerta yang berarti nawa (sembilan) dan cita (harapan, agenda, keinginan). Pemerintah menginginkan adanya revolusi terhadap bangsa Indonesia untuk menjadi lebih baik lagi dan salah satu agenda besar pemerintah yang tertuang dalam Nawacita ialah pembangunan nasional. Agenda ini dapat terealisasi dengan adanya sumber dana yang besar, karena sangat sulit mengintegrasikan seluruh wilayah indonesia yang merupakan negara kepulauan dan terdiri dari berbagai suku bangsa yang berbeda-beda. Sumber utama penerimaan negara dalam menjalankan roda pemerintahan ialah berasal dari pajak. Bisa dikatakan setiap transaksi yang ada di indonesia selalu berhubungan dengan pajak.

Pada tahun 2015 sampai dengan saat ini merupakan tahunnya bagi perusahaan jasa konstruksi, dimana banyak proyek infrastruktur pemerintah yang diberikan kepada pihak swasta untuk dikerjakan dan ada beberapa pula yang diambil alih langsung oleh BUMN dan BUMD seperti proyek LRT, MRT, Jalan Tol dan Palapa Ring. Pada sisi pemerintah, proyek ini akan cepat terselesaikan karena melibatkan banyak perusahaan swasta serta asing dan dari sisi swasta tentunya akan menambah laba mereka karena proyek tersebut dibiayai dengan dana yang sangat besar. Oleh karena itu, bagi pihak swasta untuk memaksimalkan profit yang diperoleh diperlukan manajemen yang tepat. Salah satu upaya manajemen untuk memaksimalkan laba dan meminimalisir bebannya ialah dengan adanya tax planning (perencanaan pajak). Karena bagi perusahaan, pajak merupakan beban yang dapat mengurangi laba sehingga setiap perusahaan pasti melakukan planning guna meminimalisir beban pajaknya.

Menurut Pohan (2018), Tax Planning merupakan rangkaian strategi untuk mengatur akuntansi dan keuangan perusahaan untuk meminimalkan kewajiban perpajakan dengan caracara yang tidak melanggar peraturan (In Legal Way). Dalam hal perencanaan pajak jasa konstruksi, manajemen harus mengetahui seluk beluk tentang jasa konstruksi. 
PT CAT merupakan perusahaan jasa konstruksi dengan Klasifikasi Lapangan Usaha (KLU) Utama : 42219-Konstruksi Jaringan Saluran Elektrikal dan Telekomunikasi Lainnya. Saat ini PT CAT tengah menjalankan proyek yang menjadi program Nawacita yang menjadi agenda besar pemerintah untuk mengintegrasikan jaringan internet keseluruh pelosok Indonesia

tepatnya indonesia bagian timur yaitu Pulau Papua. Proyek infrastruktur tersebut bernama Palapa Ring Timur yang diperkirakan selesai pada pertengahan tahun 2019. Oleh karena skala proyek yang besar, sehingga diperlukan perencanaan yang tepat agar dapat tercapai ekonomisasi,efisiensi dan efektifitas (3E).

Menurut UU No.18 Tahun 1999 tentang Jasa konstruksi, "Jasa Konstruksi" adalah layanan jasa konsultansi perencanaan pekerjaan konstruksi, layanan jasa pelaksanaan pekerjaan konstruksi dan layanan jasa konsultansi pengawasan pekerjaan konstruksi. Pekerjaan Konstruksi adalah keseluruhan atau sebagian rangkaian kegiatan perencanaan dan/atau pelaksanaan beserta pengawasan yang mencakup pekerjaan arsitektural, sipil, mekanikal, elektrikal dan tata lingkungan masing-masing beserta kelengkapannya untuk mewujudkan suatu bangunan. Usaha jasa konstruksi adalah usaha tentang jasa di bidang perencanaan, pelaksana dan pengawas konstruksi yang semuanya disebut penyedia jasa. Jadi pengertian utuh dari usaha jasa konstruksi adalah usaha yang berhubungan dengan perencanaan atau pelaksanaan dan pengawasan suatu kegiatan konstruksi untuk membentuk suatu bangunan atau fisik lain yang dalam penggunaan atau pemanfaatan menyangkut kepentingan dan keselamatan masyarakat pemakai serta lingkungan hidup.

Sistem perpajakan di Indonesia menganut sistem self assessment yakni Wajib Pajak diberikan kepercayaan oleh Pemerintah untuk menghitung, menyetor, dan melaporkan kewajiban perpajakannya sendiri. Namun, untuk memastikan sistem self assessment berjalan dengan baik dan sebagai alat kontrol bagi pemerintah, diterapkan pula withholding tax system atau yang lebih dikenal dengan sebutan sistem pemotongan/pemungutan oleh pihak ketiga.

Perusahaan jasa konstruksi merupakan wajib pajak yang dikenai pajak bersifat Final, artinya kewajiban pajaknya telah tuntas/selesai ketika dilakukan pemotongan/pemungutan. Akan tetapi guna meminimalisir pembayaran pajak, dibutuhkan planning yang tepat agar tidak melanggar ketentuan umum perpajakan yang berlaku sehingga tidak menyebabkan kerugian bagi negara. Setelah melakukan planning yang tepat wajib pajak diharapkan menjadi withholding tax yang benar, karena wajib pajak telah diberikan kepercayaan oleh Direktorat Jenderal Pajak sebagai pihak ketiga untuk melakukan pomotongan/pemungutan atas segala jenis transaksi yang berhubungan dengan usaha wajib pajak. Wujud sistem pemungutan pajak penghasilan wihholding tax system di Indonesia adalah Pajak Penghasilan (PPh) Pasal 21, $\mathrm{PPh}$ Pasal 22, PPh Pasal 23, PPh, PPh Pasal 26, PPh Pasal 4 ayat (2) dan PPh Pasal 15. Oleh karena luasnya sistem pemungutan withholding tax ini, wajib pajak dituntut melakukan perencanaan yang tepat agar dikemudian hari tidak mendapatkan sanksi berupa denda akibat kelalaian dalam melaksanakan pemotongan/pemungutan Pajak Penghasilan.

\section{TINJAUAN PUSTAKA}

Pengertian akuntansi Menurut Weygandt, Kimmel, dan Kieso (2013:5) adalah

"Accounting is an information system that identified, records and communicates the economic events of an organization to interested users".

Definisi ini mengandung beberapa pengertian, yaitu:

1. Bahwa akuntansi merupakan proses yang terdiri dari pengidentifikasian, pencatatan dan pengkomunikasian kejadian-kejadian ekonomi.

2. Bahwa informasi tentang kejadian ekonomi suatu organisasi yang dihasilkan oleh akuntansi diharapkan berguna bagi pihak-pihak yang berkepentingan.

Sedangkan pengertian akuntansi dalam Soekrisno Agus (2014:1) adalah sebagai berikut: "Akuntansi adalah sistem informasi yang menghasilkan laporan kepada pihak-pihak yang berkepentingan mengenai aktifitas ekonomi dan kondisi perusahaan".

Laporan keuangan adalah catatan informasi keuangan suatu perusahaan pada suatu periode akuntansi yang dapat digunakan untuk menggambarkan kinerja perusahaan tersebut. 
Kasmir (2017:7) menyatakan sebagai berikut : “ Laporan yang menunjukan kondisi keuangan perusahaan pada saat ini atau dalam suatu periode tertentu. Kondisi Keuangan perusahaan terkini adalah keadaan keuangan perusahaan pada tanggal tertentu (untuk neraca) dan periode tertentu (untuk laporan laba rugi). ".

Laporan keuangan juga memiliki karakteristik kualitatif yang merupakan ciri khas yang membuat informasi didalamnya dapat lebih bermanfaat bagi tiap pemakainya dalam mengambil keputusan.

Waluyo (2015:21) menyebutkan terdapat empat karakterisrik, yaitu:

1. Dapat dipahami

2. Relevan

3. Materialitas

4. Keandalan

Mardiasmo (2016:13) menyatakan bahwa "Pajak ialah iuran rakyat kepada kas negara berdasarkan Undang-undang serta tidak mendapat kontraprestasi secara langsung dan digunakan untuk membayar pengeluaran umum".

Adapun ciri-ciri yang melekat pada definisi pajak dalam Siti Resmi (2014:2), yaitu:

1. Pajak dipungut berdasarkan atau dengan kekuatan undang-undang serta aturan pelaksanaannya.

2. Dalam pembayaran pajak tidak dapat ditunjukkan adanya kontraprestasi individual oleh pemerintah.

3. Pajak dipungut oleh negara, baik pemerintah pusat maupun pemerintah daerah.

4. Pajak diperuntukkan bagi pengeluaran-pengeluaran pemerintah yang bila dari pemasukannya masih terdapat surplus, digunakan untuk membiayai public investment.

Menurut Mardiasmo (2018:9), sistem pemungutan pajak dapat dibagi menjadi tiga, yaitu:

1. Official Assessment System

Adalah suatu sistem pemungutan yang memberi wewenang kepada pemerintah (fiskus) untuk menentukan besarnya pajak yang terutang oleh wajib pajak.

Ciri-cirinya:

1) Wewenang untuk menentukan besarnya pajak terutang ada pada fiskus

2) Wajib pajak bersifat pasif

3) Utang pajak timbul setelah dikeluarkan surat ketetapan pajak oleh fiskus.

2. Self Assessment System

Adalah suatu sistem pemungutan pajak yang memberi wewenang kepada wajib pajak untuk menentukan sendiri besarnya pajak yang terutang.

Ciri-cirinya:

1) Wewenang untuk menentukan besarnya pajak terutang ada pada wajib pajak

2) Wajib pajak aktif mulai dari menghitung, menyetor, dan melaporkan sendiri pajak yang terutang

3) Fiskus tidak ikut campur dan hanya mengawasi

3. Witholding System

Adalah suatu sistem pemungutan pajak yang memberi wewenang kepada pihak ketiga (bukan fiskus dan bukan wajib pajak yang bersangkutan) untuk memotong atau memungut pajak terutang oleh Wajib Pajak.

Ciri-cirinya: wewenang memotong atau memungut pajak yang terutang ada pada pihak ketiga, yaitu pihak selain fiskus dan Wajib Pajak.

Menurut Waluyo (2019:35) menjelaskan akuntansi pajak sebagai berikut:"Dalam menetapkan besarnya pajak terutang tetap mendasarkan laporan keuangan yang disusun oleh perusahaan, mengingat dalam ketentuan perundang-undangan perpajakan terdapat aturan-aturan 
khusus yang berkaitan dengan akuntansi, yaitu masalah konsep transaksi dan peristiwa keuangan, metode pengukuran, serta pelaporannya yang ditetapkan oleh undang-undang".

Menurut Mardiasmo (2018:9), withholding tax system adalah suatu sistem pemungutan pajak yang memberi wewenang kepada pihak ketiga (bukan fiskus dan bukan wajib pajak yang bersangkutan) untuk memotong atau memungut pajak terutang oleh Wajib Pajak.

Konsep withholding tax system ini berbeda dengan self assessment system. Dalam withholding tax system, Wajib Pajak diberi kewajiban untuk menghitung, menyetor dan mengadministrasikan pajaknya pihak lain. Sedangkan self assessment system, Wajib Pajak diberi kewajiban untuk menghitung, menyetor dan mengadministrasikan kewajiban pajaknya sendiri.

Dalam withholding tax system yang berlaku saat ini di Indonesia, kewenangan Ditjen Pajak dalam menentukan jenis-jenis penghasilan yang merupakan objek withholding tax. Tidak adanya pembatasan mengenai jenis-jenis yang layak dan tidak layak dikenakan withholding tax tentunya akan memberikan keleluasaan bagi pemerintah untuk terus memperluas pengenaan withholding tax ini. Alasannya adalah karena penerimaan pajak akan mudah terkumpul dan tugas pemerintah (Ditjen Pajak) cukup mengawasi saja, dan kalau ada yang tidak menjalankan withholding tax system tersebut dengan benar, maka Ditjen Pajak tinggal memberikan sanksi administrasi yang tentunya akan menambah penerimaan negara. Wujud sistem pemungutan Pajak Penghasilan withholding tax di Indonesia adalah $\mathrm{PPh}$ pasal 21, PPh pasal 22, $\mathrm{PPh}$ pasal 23, PPh pasal 26, PPh Pasal 4 ayat (2) dan PPh pasal 15.

Menurut Chairil Anwar Pohan (2018:8), Tax Planning merupakan rangkaian strategi untuk mengatur akuntansi dan keuangan perusahaan untuk meminimalkan kewajiban perpajakan dengan cara-cara yang tidak melanggar peraturan (In Legal Way).

Adapun tujuan pokok yang ingin dicapai dari perencanaan pajak yang baik dalam Mardiasmo (2018:21), adalah:

1. Meminimalisasi beban pajak yang terutang.

Tindakan yang harus diambil dalam rangka perencanaan pajak tersebut berupa usaha-usaha mengefesiensikan beban pajak yang masih dalam ruang lingkup pemajakan dan tidak melanggar peraturan perpajakan.

2. Memaksimalkan laba setelah pajak.

3. Meminimalkan terjadinya kejutan pajak (tax surprise) jika terjadi pemeriksaan pajak oleh fiskus.

4. Memenuhi kewajiban perpajakannya dengan benar, efisien, dan efektif sesuai ketentuan perpajakan, yang antara lain meliputi:

a. Memenuhi segala ketentuan administrative, agar terhindar dari pengenaan sanksi, baik sanksi administrative maupun pidana seperti bunga, kenaikan, denda, dan hukum kurungan atau penjara.

b. Memenuhi secara efektif segala ketentuan undang-undang perpajakan yang terkait dengan withholding tax system ( $\mathrm{PPh}$ pasal 21, $\mathrm{PPh}$ pasal 22, $\mathrm{PPh}$ pasal 23 dan $\mathrm{PPh}$ pasal 4 ayat (2)).

Menurut Suandy (2016:135), agar tax plan berhasil sesuai dengan yang diharapkan, alternative perencanaan pajak yang dilakukan adalah:

Beberapa hal krusial yang perlu diperhatikan dalam penanganan tax planning, yaitu:

1. Masalah Pembuatan Kontrak kerja

2. Konflik dalam withholding tax

3. Ekualisasi objek withholding tax dengan laporan keuangan

Menurut UU No.18 Tahun 1999 tentang Jasa konstruksi, "Jasa Konstruksi" adalah layanan jasa konsultansi perencanaan pekerjaan konstruksi, layanan jasa pelaksanaan pekerjaan konstruksi dan layanan jasa konsultansi pengawasan pekerjaan konstruksi. "Pekerjaan Konstruksi" adalah keseluruhan atau sebagian rangkaian kegiatan perencanaan dan/atau pelaksanaan beserta pengawasan yang mencakup pekerjaan arsitektural, sipil, mekanikal, elektrikal dan tata lingkungan masing-masing beserta kelengkapannya untuk mewujudkan suatu bangunan. 
Dalam melakukan usaha jasa konstruksi, perusahaan jasa konstruksi harus memiliki Izin Usaha Jasa Konstruksi (IUJK). Menurut Peraturan Menteri Pekerjaan Umum No. 04/PRT/M/2011 tentang Pedoman Persyaratan Pemberian Izin Usaha Jasa Konstruksi Nasional, izin usaha jasa kontruksi adalah izin untuk melaksanakan usaha di bidang jasa konstruksi yang diberikan oleh Pemerintah Kota/Kabupaten. Tujuan utama dari IUJK adalah sebagai fungsi pengaturan yang diharapkan dapat memberikan pertumbuhan dan perkembangan usaha jasa konstruksi, sehingga berguna untuk mewujudkan struktur usaha yang kokoh, handal, berdaya saing tinggi serta memiliki hasil pekerjaan yang berkualitas.

Menurut Pasal 9 PP No. 28 Tahun 2000 tentang Usaha dan Peran Masyarakat Jasa Konstruksi dan kualifikasi usaha, yaitu:

a. Usaha orang perseorangan dan atau badan usaha jasa konsultansi perencanaan dan atau jasa konsultansi pengawasan konstruksi hanya dapat melakukan layanan jasa perencanaan dan pengawasan pekerjaan konstruksi sesuai dengan klasifikasi dan kualifikasi yang ditetapkan oleh lembaga.

b. Usaha orang perseorangan selaku pelaksana konstruksi yang berbentuk bukan badan hukum dapat melakukan pekerjaan konstruksi sesuai klasifikasi dan kualifikasi yang ditetapkan oleh lembaga untuk pekerjaan yang beresiko kecil, berteknologi sederhana, dan berbiaya kecil.

c. Badan usaha jasa pelaksana kontruksi yang berbentuk bukan badan hukum hanya dapat mengerjakan pekerjaan konstruksi sesuai dengan klasifikasi dan kualifikasi yang ditetapkan oleh lembaga untuk pekerjaan yang beresiko kecil sampai sedang, berteknologi sederhana sampai menengah, serta berbiaya kecil sampai sedang.

d. Badan usaha jasa konstruksi berbentuk badan hukum dapat mengerjakan pekerjaan konstruksi sesuai klasifikasi dan kualifikasi yang ditetapkan oleh lembaga.

e. Untuk pekerjaan konstruksi yang beresiko tinggi dan atau yang berteknologi tinggi dan atau berbiaya besar hanya dapat dilakukan oleh badan usaha berbentuk Perseroan Terbatas (PT) atau badan usaha asing yang dipersamakan.

Sesuai dengan dikeluarkannya Undang-undang Nomor 2 tahun 2017 tentang Jasa konstruksi, Wajib Pajak yang menjalankan usaha jasa konstruksi dikenakan Pajak Penghasilan $(\mathrm{PPh})$ yang bersifat FINAL dengan menggunakan tarif tertentu sesuai dengan Peraturan Pemerintah Nomor 40 tahun 2009 tentang Perubahan atas Peraturan Pemerintah Nomor 51 tahun 2008 yang mengatur tentang perpajakan jasa konstruksi terkait layanan jasa sehubungan kegiatan yang dilakukan, selain Pajak Pertambahan Nilai (PPN) bagi yang terdaftar sebagai Pengusaha Kena Pajak (PKP). Pajak Penghasilan (PPh) bersifat FINAL dapat diartikan sebagai berikut:

a. PPh dihitung berdasarkan penghasilan bruto tanpa memperhitungkan biaya-biaya untuk memperoleh, menagih, dan memelihara penghasilan.

b. Dikenakan tarif dan DPP tertentu diatur dengan PP dan PMK.

c. Jumlah PPh yang dipotong pihak lain atau dibayar sendiri tidak dapat dikreditkan pada SPT Tahunan.

Tabel 1. Klasifikasi dan Kualifikasi Jasa Konstruksi

\begin{tabular}{|l|l|c|c|c|}
\hline \multicolumn{1}{|c|}{ Jenis Jasa } & \multicolumn{1}{|c|}{$\begin{array}{c}\text { Penyelenggara } \\
\text { Kegiatan }\end{array}$} & Grade & Tarif & $\begin{array}{c}\text { Jenis } \\
\text { Pajak }\end{array}$ \\
\hline \multirow{3}{*}{$\begin{array}{l}\text { Pelaksana } \\
\text { Konstruksi }\end{array}$} & Kualifikasi Kecil & 1 s.d 4 & $2 \%$ & \\
\cline { 2 - 4 } & Kualifikasi Menengah & 5 & $3 \%$ & \multirow{2}{*}{ PPh } \\
\cline { 2 - 4 } & Kualifikasi Besar & 6 s.d 7 & $3 \%$ & \\
\cline { 2 - 4 } & Non Kualifikasi & & $4 \%$ & \\
\hline
\end{tabular}




\begin{tabular}{|l|l|c|c|c|}
\hline $\begin{array}{l}\text { Perencanaan dan } \\
\text { Pengawasan } \\
\text { Konstruksi }\end{array}$ & Mempunyai Kualifikasi & & $4 \%$ & \multirow{2}{*}{} \\
\cline { 2 - 2 } & $\begin{array}{l}\text { Tidak Mempunyai } \\
\text { Kualifikasi }\end{array}$ & $6 \%$ & \\
\hline \multicolumn{2}{|l|}{ Penyerahaan dalam negeri } & $10 \%$ & PPN \\
\hline \multicolumn{2}{|l|}{ Penyerahaan Luar Pabean (ekspor) } & $0 \%$ & \\
\hline
\end{tabular}

Sumber: Leaflet Jasa Konstruksi

Untuk pengusaha, atau badan usaha yang tidak teregistrasi dalam Lembaga Pengembangan Jasa Konstruksi (LPJK) dan tidak memiliki Sertifikasi Badan Usaha (SBU), maka pengenaan pajak penghasilan atas imbalan yang diterima tidak menjadi objek pajak PPh Final Pasal 4 ayat (2) jasa konstruksi. Imbalan tersebut akan masuk dalam objek PPh pasal 23, hal ini terjadi jika penerima penghasilannya ialah wajib pajak badan dalam negeri, sedangkan jika merupakan wajib pajak orang pribadi maka akan dikenakan PPh Pasal 21. Kemudian untuk wajib pajak yang memiliki Sertifikasi Badan Usaha (SBU) tetapi sudah tidak berlaku/tidak memperpanjang masa berlakunya, maka akan dikenakan tarif pajak sesuai yang dijelaskan diatas, yaitu $4 \%$ untuk pelaksana konstruksi dan $6 \%$ untuk perencana atau pengawas konstruksi. Dalam pemenuhan kewajibannya Perusahaan Jasa Konstruksi berkewajiban melakukan Pemotongan/Pemungutan PPh (Witholding Tax) sesuai yang tercantum dalam Surat Keterangan Terdaftar yang diperoleh Wajib Pajak dari Kantor Pelayanan Pajak tempat Wajib Pajak terdaftar.

\section{METODE}

Metode pengumpulan data yang digunakan dalam penelitian ini adalah sebagai berikut:

1. Studi Lapangan (Field Research)

Yaitu penelitian dengan cara mendatangi langsung ke perusahaan yang menjadi objek penelitian. Teknik pengumpulan data dilakukan dengan observasi atau pengamatan secara sistematik dimana data-data tersebut mempunyai kebenaran/keabsahan, sehingga penulis dapat mempertanggung jawabkan tulisan ini.

2. Studi Kepustakaan (Library Research)

Penulis menggunakan dan mengumpulkan data-data dari berbagai literature yang dapat digunakan sebagai konsep dan landasan teori untuk pemecahan masalah yang berkaitan dengan permasalahan yang ada pada penelitian ini.

3. Wawancara (Interview)

Penulis melakukan wawancara secara langsung dengan pihak perusahaan yang memiliki wewenang dalam memberikan informasi dan data yang berkaitan dengan penelitian. Wawancara dilakukan dengan meminta keterangan dari Manager Finance, Accounting dan Tax. Hasil wawancara tersebut antara lain mengenai Tax Planning atas Withholding Tax Pada PT. CAT.

\section{HASIL DAN PEMBAHASAN}

PT. CAT merupakan perusahaan yang bergerak dibidang jasa konstruksi sehingga dikenakan pajak bersifat final yaitu PPh 4 ayat (2). Dibawah ini merupakan beban pajak yang dipotong/pungut berdasarkan penghasilan yang diterina PT. CAT pada tahun 2018.

Tabel 2. Penghasilan PT. CAT tahun 2018

\begin{tabular}{|l|r|c|c|}
\hline \multicolumn{1}{|c|}{ Masa Pajak } & Penghasilan & Tarif & PPh pasal 4 ayat 2 \\
\hline Januari & - & $3 \%$ & - \\
\hline
\end{tabular}




\begin{tabular}{|l|r|r|c|} 
Februari & & $3 \%$ & - \\
\hline Maret & 256.205 .169 & $3 \%$ & 7.686 .155 \\
\hline April & - & $3 \%$ & - \\
\hline Mei & - & $3 \%$ & - \\
\hline Juni & 58.172 .233 .414 & $3 \%$ & 1.745 .167 .002 \\
\hline Juli & 11.309 .535 .461 & $3 \%$ & 339.286 .063 \\
\hline Agustus & - & $3 \%$ & - \\
\hline September & 126.068 .628 & $3 \%$ & 3.782 .059 \\
\hline Oktober & 471.124 .500 & $3 \%$ & 14.133 .735 \\
\hline Nopember & 251.343 .628 & $3 \%$ & 7.540 .308 \\
\hline Desember & - & $3 \%$ & - \\
\hline \multicolumn{2}{|r|}{ Total PPh pasal 4 ayat (2) } \\
\hline
\end{tabular}

Subkualifikasi PT. CAT ialah Menengah Satu (M1) termasuk dalam grade 5, sehingga dikenakan PPh Pasa 4 ayat (2) atas jasa konstruksi dengan tarif 3\% dari penghasilan yang diterima sebelum PPN.

\section{Biaya-biaya yang merupakan objek withholding tax}

Sehubungan dengan kegiatan usahanya, setiap perusahaan pasti mengeluarkan biayabiaya guna memperoleh pendapatan. Dari setiap biaya yang dikeluarkan, hampir semua biayabiaya merupakan objek Pajak Penghasilan, mengingat tidak adanya pembatasan penghasilan yang merupakan objek withholding tax. Berikut ini merupakan rincian biaya-biaya yang termasuk objek Pajak Penghasilan Pasal 21, Pasal 22, Pasal 23 dan Pasal 4 ayat (2) yang diperoleh selama penelitian.

a. Biaya sehubungan dengan objek PPh Pasal 21

Tabel 3. Rincian gaji dan PPh pasal 21 tahun 2018

\begin{tabular}{|c|c|c|}
\hline \multirow{2}{*}{ Masa Pajak } & Pegawai Tetap & \multirow{2}{*}{ PPh 21} \\
\hline & Penghasilan Bruto & \\
\hline Januari & 753.126 .524 & 24.425 .514 \\
\hline Februari & 812.632 .465 & 24.792 .267 \\
\hline Maret & 888.185 .103 & 24.742 .604 \\
\hline April & 1.004 .054 .482 & 24.463 .118 \\
\hline Mei & 1.063 .126 .312 & 24.541 .284 \\
\hline Juni & 1.599 .425 .716 & 41.910 .432 \\
\hline Juli & 1.021 .786 .426 & 25.381 .147 \\
\hline Agustus & 1.147 .861 .672 & 25.732 .601 \\
\hline September & 1.251 .930 .617 & 25.923 .837 \\
\hline Oktober & 1.409 .855 .813 & 26.207 .759 \\
\hline Nopember & 1.309 .598 .104 & 25.092 .623 \\
\hline Desember & 1.242 .403 .822 & 44.970 .847 \\
\hline Jumlah & 13.503.987.56 & 338.184 .033 \\
\hline
\end{tabular}

PT.CAT menggunakkan metode gross up dalam menghitung PPh Pasal 21 terutang dan menghasilkan beban gaji dan tunjangan sebesar Rp. 13.503.987.056. Dalam pelaksanaan tax 
planning diketahui, jika perusahaan sedang mengalami kerugian atau perusahaan tersebut merupakan Wajib Pajak yang dikenakan pajak bersifat final. Lebih tepat menggunakan alternatif tax planning dengan memberikan natura yang bukan merupakan objek pajak daripada memberikan tunjangan, sebab pemberian tunjangan pajak membuat inefisiensi terhadap beban pajak pada perusahaan dengan kriteria tersebut. Karena perusahaan ingin memberikan benefit in kind kepada pegawainya. Penelitian ini dilakukan dengan membandingkan metode gross up dan metode nett dalam perhitungan PPh Pasal 21 nya.

Tabel 4. Daftar Gaji Karyawan PT. CAT tahun 2018

\begin{tabular}{|c|c|c|c|}
\hline \multirow[t]{2}{*}{ NAMA } & GAJI SETAHUN & THR & $\begin{array}{c}\text { Tunjangan } \\
\text { Pajak }=\text { PPh Pasl } \\
21\end{array}$ \\
\hline & 1 & 2 & 3 \\
\hline ANGGIAT & 204.532 .316 & - & 17.240 .950 \\
\hline Tn. A & 382.824 .978 & - & 61.608 .250 \\
\hline Tn. B & 249.341 .865 & - & 24.354 .400 \\
\hline Tn. C & 259.373 .251 & - & 26.124 .550 \\
\hline Tn. D & 255.341 .865 & - & 26.207 .350 \\
\hline Tn. E & 291.641 .015 & - & 32.713 .500 \\
\hline Tn. F & 118.148 .149 & 4.959 .823 & 2.871 .850 \\
\hline Tn. G & 55.445 .853 & 7.042 .221 & 281.550 \\
\hline Tn. H & 131.253 .852 & 5.961 .803 & 4.567 .450 \\
\hline Tn. I & 69.020 .372 & 3.610 .115 & 78.650 \\
\hline Tn. J & 130.361 .694 & 9.313 .150 & 5.795 .500 \\
\hline Tn. K & 87.606 .315 & 4.013 .354 & 1.025 .650 \\
\hline Tn. AA & 61.571 .438 & 4.409 .455 & 219.500 \\
\hline Tn. AB & 69.139 .875 & 3.409 .000 & 310.800 \\
\hline Tn. BB & 66.964 .164 & 3.206 .876 & 428.450 \\
\hline Tn. CC & 114.504 .944 & 5.727 .293 & 2.222 .700 \\
\hline Tn. DD & 159.680 .420 & - & 9.325 .900 \\
\hline Tn. EE & 67.280 .648 & 4.787 .814 & 759.300 \\
\hline Tn. FF & 133.695 .993 & 8.005 .367 & 5.359 .000 \\
\hline Tn. GG & 77.831 .067 & 3.162 .215 & 495.700 \\
\hline Tn. HH & 83.415 .347 & 3.802 .406 & 1.514 .750 \\
\hline Tn. II & 158.860 .769 & 10.356 .605 & 11.008 .900 \\
\hline Tn. JJ & 141.340 .867 & 7.200 .141 & 7.360 .150 \\
\hline Tn. KK & 61.988 .331 & 1.012 .960 & 70.900 \\
\hline Tn. BA & 75.065 .660 & 5.336 .981 & 466.250 \\
\hline Tn. BC & 93.787 .797 & 2.755 .860 & 1.271 .200 \\
\hline Tn. BD & 72.989 .986 & 3.408 .495 & 266.550 \\
\hline Tn. BE & 113.602 .208 & 2.000 .164 & 2.221 .600 \\
\hline Tn. CA & 225.356 .380 & - & 20.915 .800 \\
\hline Tn. CB & 107.320 .157 & 3.504 .674 & 2.455 .800 \\
\hline Tn. CD & 212.506 .077 & - & 18.648 .100 \\
\hline Tn. CE & 78.527 .294 & 3.508 .486 & 1.256 .350 \\
\hline Tn. DA & 131.481 .239 & 7.694 .602 & 6.501 .550 \\
\hline Tn. DB & 122.563 .265 & 4.994 .789 & 3.657 .250 \\
\hline Tn. DC & 153.166 .742 & 8.004 .313 & 11.177 .200 \\
\hline Tn. DE & 87.698 .044 & 2.129 .167 & 1.408 .700 \\
\hline Tn. EA & 172.272 .097 & 12.370 .672 & 13.730 .950 \\
\hline Tn. EB & 104.754 .432 & 2.710 .294 & 2.052 .000 \\
\hline Tn. EC & 100.405 .183 & 5.852 .508 & 1.991 .850 \\
\hline
\end{tabular}




\begin{tabular}{|l|r|r|r|} 
Tn. ED & 76.856 .589 & 5.250 .556 & 1.259 .900 \\
\hline Tn. FA & 119.680 .870 & 9.342 .638 & 6.298 .150 \\
\hline Tn. FB & 74.210 .347 & 5.326 .668 & 659.130 \\
\hline $\begin{array}{l}\text { Karyawan Dibawah PTKP } \\
(178 \text { orang) }\end{array}$ & 7.438 .221 .809 & & \\
\hline \multicolumn{1}{|c|}{ Jumlah } & $\mathbf{1 2 . 9 9 1 . 6 3 1 . 5 6 4}$ & $\mathbf{1 7 4 . 1 7 1 . 4 6 5}$ & $\mathbf{3 3 8 . 1 8 4 . 0 3 3}$ \\
\hline
\end{tabular}

Dari tabel diatas dapat dilihat bahwa PT. CAT memberikan natura (benefit in kind) berupa tunjangan pajak kepada karyawan yang menerima penghasilan diatas Penghasilan tidak kena pajak (PTKP). Untuk memperoleh perhitungan besaran tunjangan pajak, perusahaan harus melakukan perhitungan PPh Pasal 21 menggunakan metode gross atau nett terlebih dahulu. Untuk memperjelas rincian diatas berikut merupakan perhitungan PPh Pasal 21 salah satu karyawan PT. CAT.

Tuan Anggiat, pegawai tetap PT. CAT sejak tahun 2018, status K/2, tahun 2018 menerima penghasilan dengan perhitungan $\mathrm{PPh}$ Pasal 21 sebagai berikut:

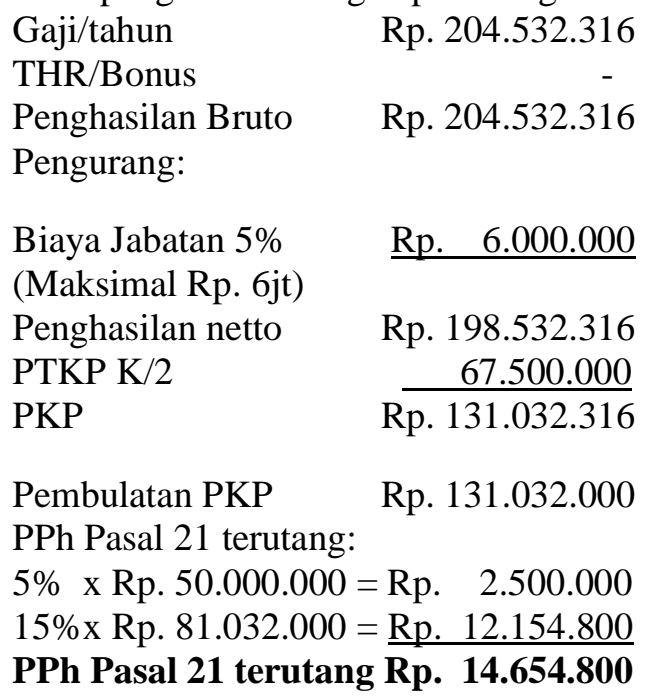

Dari contoh tersebut bisa dilihat Penghasilan Kena Pajak (PKP) dengan metode gross/nett. Setelah itu baru dilakukan perhitungan dengan metode gross up.

Rumus Perhitungan PPh Pasal 21 gross up:

a. Lapisan 1: Untuk PKP $0-47.500 .000$ Tunjangan $\mathrm{PPh}=(\mathrm{PKP}$ setahun -0$) \times 5 / 95+0$

b. Lapisan 2: Untuk PKP 47.500.000 sampai dengan 217.500.000 Tunjangan $\mathrm{PPh}=(\mathrm{PKP}$ setahun $-47.500 .000) \times 15 / 85+2.500 .000$

c. Lapisan 3: Untuk PKP 217.500.000 sampai dengan 405.000.000 Tunjangan $\mathrm{PPh}=(\mathrm{PKP}$ setahun $-217.500 .000) \times 25 / 75+32.500 .000$

d. Lapisan 4: Untuk PKP > 405.000.000 Tunjangan $\mathrm{PPh}=(\mathrm{PKP}$ setahun $-405.000 .000) \times 30 / 70+95.000 .000$

Jika dilihat dari perhitungan PPh sebelumnya dengan metode gross/nett, diketahui bahwa penghasilan kena pajak Tuan Anggiat sebesar Rp. 131.032.000, artinya Tuan Anggiat termasuk dalam kategori lapisan dua pada metode perhitungan gross up.

Berikut perhitungan dengan metode gross up.

PKP Rp.131.032.000

Tunjangan $P P h=(131.032 .000-47.500 .000) \times 15 / 85+2.500 .000$ 
Nurwati \& Syaiful Anwar

$=83.532 .000 \times 15 / 85+2.500 .000$

$=$ Rp. 17.240.950

Pembuktian metode gross up.

Gaji/Tahun Rp. 204.532.316

Tunjangan Pajak Rp. 17.240.950

THR

Pengurang:

Rp.221.773.266

Biaya Jabatan 5\% Rp. $\quad 6.000 .000$

PTKP K/2 Rp.215.773.266

PKP Rp.148.273.266

Pembulatan Rp. 148.273 .000

PPh Pasal 21:

$5 \%$ x $50.000 .000=$ Rp. 2.500 .000

$15 \%$ x $98.273 .0000=$ Rp. 14.740 .950

PPh Pasal 21

Rp. 17.240.950,-

Setelah dilakukan perhitungan ulang terhadap PPh Pasal 21 dengan menggunakan metode nett, ditemukan hasil PPh terutang atas seluruh karyawan sebesar Rp. 284.922.159.

Tabel 5.Rincian PPh Pasal 21 metode nett

\begin{tabular}{|c|c|c|c|}
\hline \multirow{2}{*}{ NAMA } & GAJI SETAHUN & THR & PPH 21 \\
\hline & 1 & 2 & 9 \\
\hline ANGGIAT & 204.532 .316 & - & 14.654 .800 \\
\hline Tn. A & 382.824 .978 & - & 46.206 .000 \\
\hline Tn. B & 249.341 .865 & - & 21.376 .150 \\
\hline Tn. C & 259.373 .251 & - & 22.205 .950 \\
\hline Tn. D & 255.341 .865 & - & 22.276 .150 \\
\hline Tn. E & 291.641 .015 & - & 27.721 .150 \\
\hline Tn. F & 118.148 .149 & 4.959 .823 & 2.480 .350 \\
\hline Tn. G & 55.445 .853 & 7.042 .221 & 268.150 \\
\hline Tn. H & 131.253 .852 & 5.961 .803 & 3.882 .250 \\
\hline Tn. I & 69.020 .372 & 3.610 .115 & 74.900 \\
\hline Tn. J & 130.361 .694 & 9.313 .150 & 4.926 .100 \\
\hline Tn. K & 87.606 .315 & 4.013 .354 & 976.900 \\
\hline Tn. AA & 61.571 .438 & 4.409 .455 & 209.050 \\
\hline Tn. AB & 69.139 .875 & 3.409 .000 & 296.050 \\
\hline Tn. BB & 66.964 .164 & 3.206 .876 & 408.100 \\
\hline Tn. CC & 114.504 .944 & 5.727 .293 & 2.111 .600 \\
\hline Tn. DD & 159.680 .420 & - & 7.927 .000 \\
\hline Tn. EE & 67.280 .648 & 4.787 .814 & 723.250 \\
\hline Tn. FF & 133.695 .993 & 8.005 .367 & 4.555 .150 \\
\hline
\end{tabular}




\begin{tabular}{|l|r|r|r|}
\hline Tn. GG & 77.831 .067 & 3.162 .215 & 472.150 \\
\hline Tn. HH & 83.415 .347 & 3.802 .406 & 1.442 .800 \\
\hline Tn. II & 158.860 .769 & 10.356 .605 & 9.357 .550 \\
\hline Tn. JJ & 141.340 .867 & 7.200 .141 & 6.256 .150 \\
\hline Tn. KK & 61.988 .331 & 1.012 .960 & 67.550 \\
\hline Tn. BA & 75.065 .660 & 5.336 .981 & 444.100 \\
\hline Tn. BC & 93.787 .797 & 2.755 .860 & 1.210 .800 \\
\hline Tn. BD & 72.989 .986 & 3.408 .495 & 253.900 \\
\hline Tn. BE & 113.602 .208 & 2.000 .164 & 2.116 .100 \\
\hline Tn. CA & 225.356 .380 & & - \\
\hline Tn. CB & 107.320 .157 & 3.504 .674 & 17.778 .400 \\
\hline Tn. CD & 212.506 .077 & & 2.339 .150 \\
\hline Tn. CE & 78.527 .294 & 3.508 .486 & 15.850 .900 \\
\hline Tn. DA & 131.481 .239 & 7.694 .602 & 1.196 .650 \\
\hline Tn. DB & 122.563 .265 & 4.994 .789 & 5.526 .250 \\
\hline Tn. DC & 153.166 .742 & 8.004 .313 & 3.783 .700 \\
\hline Tn. DE & 87.698 .044 & 2.129 .167 & 9.500 .650 \\
\hline Tn. EA & 172.272 .097 & 12.370 .672 & 1.341 .750 \\
\hline Tn. EB & 104.754 .432 & 2.710 .294 & 11.671 .300 \\
\hline Tn. EC & 100.405 .183 & 5.852 .508 & 1.954 .550 \\
\hline Tn. ED & 76.856 .589 & 5.250 .556 & 1.897 .200 \\
\hline Tn. FA & 119.680 .870 & 9.342 .638 & 1.200 .050 \\
\hline Tn. FB & 74.210 .327 & 5.326 .668 & 5.353 .450 \\
\hline$<$ PTKP & 1249.440 .253 & 188.781 .556 & 628.000 \\
\hline & & & - \\
\hline & & & 284.922 .159 \\
\hline & & & \\
\hline
\end{tabular}

Dari tabel 4 dan 5 dapat dilakukan analisis terhadap perhitungan PPh Pasal 21 pada PT. CAT sebagai berikut:

Tabel 6. Analisis Perhitungan PPh Pasal 21 tahun 2018

\begin{tabular}{|l|c|r|}
\hline \multicolumn{1}{|c|}{ Uraian } & \multicolumn{1}{|c|}{$\begin{array}{c}\text { Ditanggung } \\
\text { Perusahaan } \\
\text { (Nett) }\end{array}$} & $\begin{array}{c}\text { Tunjangan } \\
\text { Pajak } \\
\text { Gross Up }\end{array}$ \\
\hline Gaji/Tahun & 5.553 .409 .754 & 5.553 .409 .754 \\
\hline Bonus/THR & 174.171 .465 & 174.171 .465 \\
\hline Tunjangan Pajak & & 338.184 .033 \\
\hline Penghasilan Bruto & 5.727 .581 .219 & 6.065 .765 .252 \\
\hline (-) Biaya Jabatan & 214.286 .068 & 215.310 .798 \\
\hline Penghasilan Netto & 5.513 .295 .151 & 5.850 .454 .454 \\
\hline (-) PTKP & 2.695 .500 .000 & 2.695 .500 .000 \\
\hline
\end{tabular}




\begin{tabular}{|l|r|r|} 
PKP & 2.817 .795 .151 & 3.154 .954 .454 \\
\hline PPh Pasal 21 & 284.922 .159 & 338.184 .033 \\
\hline Tunjangan Pajak & - & 338.184 .033 \\
\hline PPh Pasal 21 yang harus disetor & 284.922 .159 & - \\
\hline
\end{tabular}

Analisis perhitungan PPh Pasal 21 pada tabel 3 dibuat berdasarkan gaji karyawan PT. CAT yang memperoleh penghasilan diatas Penghasilan Tidak Kena Pajak (PTKP)

Selanjutnya pada tabel 4 berikut ini, dapat dilihat gambaran alternatif yang paling menguntungkan bagi perusahaan dan bagi pegawai dalam pemilihan dari kedua alternatif kebijakan perhitungan PPh Pasal 21.

Tabel 7. Take Home Pay (THP)

\begin{tabular}{|l|c|r|}
\hline \multicolumn{1}{|c|}{ Uraian } & $\begin{array}{c}\text { Ditanggung } \\
\text { Perusahaan } \\
\text { (Nett) }\end{array}$ & \multicolumn{1}{c|}{$\begin{array}{c}\text { Tunjangan } \\
\text { Pajak } \\
\text { (Gross Up) }\end{array}$} \\
\hline Gaji/Tahun & 12.802 .850 .002 & 12.802 .850 .002 \\
\hline Bonus/THR & 362.953 .021 & 362.953 .021 \\
\hline Tunjangan Pajak & & 338.184 .033 \\
\hline Penghasilan Bruto & 13.165 .803 .023 & 13.503 .987 .056 \\
\hline PPh Pasal 21 & - & 338.184 .033 \\
\hline Total Take Home Pay & 13.165 .803 .023 & 13.165 .803 .023 \\
\hline
\end{tabular}

Berdasarkan analisis pada tabel 3 hingga tabel 6, dapat diuraikan sebagai berikut:

1. Take Home Pay

Secara umum, kedua metode perhitungan $\mathrm{PPh}$ Pasal 21 menghasilkan take home pay yang sama. Artinya kedua metode tersebut menguntungkan bagi pegawai. Take home pay pada tabel. 14 merupakan take home pay keseluruhan pegawai pada tahun 2018 berdasarkan akun beban gaji pada laporan keuangan.

2. PPh Pasal 21 ditanggung perusahaan (Nett method)

Dalam metode ini, PPh Pasal 21 yang terutang akan ditanggung oleh perusahaan sebesar Rp. 284.922.159. Dari sisi pegawai gaji yang diterima tidak dipotong PPh Pasal 21, karena perusahaanlah yang menanggung PPh Pasal 21. Oleh karena, jumlah PPh Pasal 21 yang ditanggung perusahaan tidak dimasukkan dalam SPT PPh Pasal 21, maka atas biaya PPh Pasal 21 yang dikeluarkan termasuk non deductible expense, yang artinya tidak boleh dikurangkan dari penghasilan bruto perusahaan.

3. PPh Pasal 21 ditunjang perusahaan seluruhnya (gross up method)

Dalam penerapan rumus gross up, perhitungan PPh Pasal 21 dilakukan dengan dua tahap seperti yang diterapkan PT. CAT. Jumlah PPh Pasal 21 yang ditunjang seluruhnya oleh perusahaan sebesar Rp. 338.184.033. Terhadap keseluruhan PPh tersebut dapat dibiayakan (deductible expense). Akan tetapi, bagi perusahaan yang dikenakan pajak final, PPh Pasal 21 gross up dinilai sebagai inefisiensi biaya walaupun sifatnya deductible expense. Hal itu dikarenakan berapapun besaran biaya yang dikeluarkan, bagi perusahaan yang dikenakan pajak final seluruh biaya akan dikoreksi fiskal positif dan tidak berpengaruh terhadap $\mathrm{PPh}$ Badan Perusahaan.

Dari data-data diatas tersebut selanjutnya dibuat perbandingan antara total beban pajak perusahaan dari PPh Pasal 21 dan PPh Badan setelah perencanaan pajak PT. CAT untuk menganalisis seberapa besar dampak perencanaan pajak tersebut pada pencapaian efisiensi pajak perusahaan.

Tabel 8. Perbandingan total beban pajak setelah perencanaan pajak

\section{Uraian}




\begin{tabular}{|l|r|r|}
\hline \multirow{2}{*}{} & \multirow{2}{*}{$\begin{array}{c}\text { Tunjangan } \\
\text { Pajak } \\
\text { Gross Up }\end{array}$} & \multicolumn{1}{|c|}{$\begin{array}{c}\text { Ditanggung } \\
\text { Perusahaan } \\
\text { (Nett) }\end{array}$} \\
\cline { 3 - 3 } & Sebelum tax planning & Setelah tax planning \\
\hline PPh Pasal 21 (sebagai tunjangan Pajak) & 338.184 .033 & - \\
\hline $\begin{array}{l}\text { PPh Pasal 21 (beban perusahaan, } \\
\text { bukan sebagai tunjangan pajak) }\end{array}$ & - & 284.922 .159 \\
\hline PPh Badan & 2.117 .595 .322 & 2.117 .595 .322 \\
\hline Total Pajak (Beban Perusahaan) & 2.455 .779 .355 & 2.402 .517 .481 \\
\hline Selisih (Efisiensi Pajak) & - & 53.261 .874 \\
\hline
\end{tabular}

Dari hasil analisis diatas, dapat dikatakan bahwa penggunaan metode net dalam perhitungan PPh Pasal 21 terutang pada PT. CAT akan menghasilkan penghematan pajak sebesar Rp.53.261.874 (2.455.779.355 - 2.402.517.481) dibandingkan dengan menggunakan metode gross up. Hal ini dikarenakan PT.CAT merupakan Wajib Pajak yang dikenakan pajak bersifat final yang mana beban pajak yang diperoleh lebih kecil daripada menggunakan metode gross up. Kerugian bagi Wajib Pajak yang dikenakan pajak bersifat final adalah walaupun pada laporan keuangan terlihat bahwa perusahaan dalam keadaan rugi, akan tetap dikenakan pajak karena dalam menghitung PPh Badan terutang tidak berdasarkan laba/rugi perusahaan tetapi berdasarkan penghasilan bruto perusahaan. Terlebih lagi $\mathrm{PPh}$ Badan perusahaan tersebut merupakan objek withholding tax Wajib Pajak lain, sehingga pada saat penyampaian SPT Tahunan Badan status SPTnya ialah NIHIL, karena PPh Badan perusahaan telah dihitung dan disetor oleh withholder.

b. Biaya-biaya yang merupakan objek PPh Pasal 22 Impor

Pada tahun 2018, PT. CAT mengeluarkan biaya-biaya sehubungan dengan impor yang merupakan objek PPh Pasal 22 Impor. Tax planning yang dilakukan perusahaan telah sesuai dengan ketentuan perpajakan yang berlaku yaitu PER-21/PJ/2014 yang mengatur tentang tata cara pengajuan permohonan pembebasan dari pemotongan dan/atau pemungutan pajak oleh pihak lain. PPh Pasal 22 Impor merupakan kredit pajak yang dapat diperhitungkan, karena PT. CAT merupakan Wajib Pajak yang dikenakan penghasilan bersifat Final, untuk menghindari SPT Tahunan Lebih bayar dan inefisiensi terhadap beban pajak, perusahaan melakukan permohonan Surat Keterangan Bebas (SKB) PPh Pasal 22 Impor agar perusahaan tidak dilakukan pemungutan $\mathrm{PPh}$ oleh Bea dan Cukai atas transaksi impornya.

c. Biaya sehubungan objek PPh Pasal 23

Tabel 9. Perhitungan PPh Pasal 23 tahun 2018

\begin{tabular}{|c|l|r|r|r|}
\hline Masa Pajak & \multicolumn{1}{|c|}{ Jenis Biaya } & DPP & TARIF & PPH Pasal 23 \\
\hline Januari & Freight Domestic & 943.950 .000 & $2 \%$ & 18.879 .000 \\
\hline \multicolumn{2}{|c|}{ TOTAL JANUARI } & & & $\mathbf{1 8 . 8 7 9 . 0 0 0}$ \\
\hline Februari & Jasa Survey & 88.000 .000 & $2 \%$ & 1.760 .000 \\
& Jasa Logistik & 1.173 .275 .488 & $2 \%$ & 23.465 .510 \\
& Jasa Konsultasi & 110.000 .000 & $2 \%$ & 2.200 .000 \\
& Jasa Outsourcing & 9.464 .626 & $2 \%$ & 189.293 \\
\hline \multicolumn{2}{|c|}{ TOTAL FEBRUARI } & & & $\mathbf{2 7 . 6 1 4 . 8 0 2}$ \\
\hline Maret & Jasa Logistik & 5.015 .725 .674 & $2 \%$ & 100.314 .513 \\
& Jasa Outsourcing & 18.189 .173 & $2 \%$ & 363.783 \\
\multicolumn{2}{|c|}{ TOTAL MARET } & 14.000 .000 & $2 \%$ & 280.000 \\
\hline \multicolumn{2}{|c|}{ Sewa Drum Truck } & & & $\mathbf{1 0 0 . 9 5 8 . 2 9 7}$ \\
\hline
\end{tabular}


Nurwati \& Syaiful Anwar

\begin{tabular}{|c|c|c|c|c|}
\hline \multirow[t]{5}{*}{ April } & Jasa Teknik & 466.500 .000 & $2 \%$ & 9.330 .000 \\
\hline & Sewa Kendaraan & 158.542 .178 & $2 \%$ & 3.170 .844 \\
\hline & Jasa Logistik & 2.276 .431 .418 & $2 \%$ & 45.528 .628 \\
\hline & Jasa Survey & 9.208 .749 & $2 \%$ & 184.175 \\
\hline & Jasa Outsourcing & 948.926 .723 & $2 \%$ & 18.978.534 \\
\hline \multicolumn{2}{|c|}{ TOTAL APRIL } & & & 77.192 .181 \\
\hline \multirow[t]{4}{*}{ Mei } & Sewa Kendaraan & 350.000 .000 & $2 \%$ & 7.000 .000 \\
\hline & Jasa Logistik & 51.066 .426 & $2 \%$ & 1.021 .329 \\
\hline & Jasa Teknik & 237.000 .000 & $2 \%$ & 4.740 .000 \\
\hline & Jasa Outsourcing & 3.210 .472 & $2 \%$ & 64.209 \\
\hline \multicolumn{2}{|c|}{ TOTAL MEI } & & & 12.825 .538 \\
\hline \multirow[t]{5}{*}{ Juni } & Sewa Alat & 146.500 .000 & $2 \%$ & 2.930 .000 \\
\hline & Jasa Logistik & 1.582 .854 .530 & $2 \%$ & 31.657 .091 \\
\hline & Jasa Teknik & 351.999 .858 & $2 \%$ & 7.039 .997 \\
\hline & Jasa Outsourcing & 20.421 .189 & $2 \%$ & 408.424 \\
\hline & freight forwarding & 10.958 .375 & $2 \%$ & 219.168 \\
\hline \multicolumn{2}{|c|}{ TOTAL JUNI } & & & 42.254 .679 \\
\hline Juli & Jasa Logistik & 671.300 .000 & $2 \%$ & 13.426 .000 \\
\hline \multicolumn{2}{|c|}{ TOTAL JULI } & & & 13.426 .000 \\
\hline \multirow[t]{2}{*}{ Agustus } & Jasa Logistik & 435.954 .428 & $2 \%$ & 8.719 .089 \\
\hline & Jasa Outsourcing & 21.287 .623 & $2 \%$ & 425.752 \\
\hline \multicolumn{2}{|c|}{ TOTAL AGUSTUS } & & & 9.144 .841 \\
\hline September & Jasa Logistik & 26.500 .000 & $2 \%$ & 530.000 \\
\hline \multicolumn{2}{|c|}{ TOTAL SEPTEMBER } & & & 530.000 \\
\hline \multirow[t]{2}{*}{ Oktober } & Jasa Logistik & 104.835 .050 & $2 \%$ & 2.096 .701 \\
\hline & Manajemen Fee & 51.533 .900 & $2 \%$ & 1.030 .678 \\
\hline \multicolumn{2}{|c|}{ TOTAL OKTOBER } & & & 3.127.379 \\
\hline \multirow[t]{2}{*}{ November } & Jasa Logistik & 45.615 .792 & $2 \%$ & 912.316 \\
\hline & Handling Fee & 4.690 .000 & $2 \%$ & 93.800 \\
\hline \multicolumn{2}{|c|}{ TOTAL NOVEMBER } & & & 1.006.116 \\
\hline Desember & Jasa Logistik & 82.500 .000 & $2 \%$ & 1.650 .000 \\
\hline \multicolumn{2}{|c|}{ TOTAL DESEMBER } & & & 1.650 .000 \\
\hline
\end{tabular}

Sumber: Data diolah

PT. CAT telah melakukan kewajiban pemotongan/pemungutan PPh sesuai dengan Undang-undang dan ketentuan perpajakan yang berlaku. Pada tabel pemotongan objek PPh Pasal 23 dapat dilihat bahwa perusahaan telah memotong/memungut $\mathrm{PPh}$ sebesar $2 \%$ atas biaya yang dikeluarkan sesuai dengan ketentuan UU PPh Pasal 23 yang mengatur tentang tarif pajak atas sewa aset yang dikecualikan dari PPh 4 ayat (2) dan atas jasa lainnya sesuai dengan PMK141/PMK.03/2015 yang mengatur tentang jasa lainnya yang dikenakan PPh Pasal 23.

d. Biaya sehubungan PPhPasal 4 ayat (2)

Tabel 10. Perhitungan PPh Pasal 4 ayat 2 tahun 2018

\begin{tabular}{|l|l|c|c|c|}
\hline \multicolumn{1}{|c|}{ Masa } & JENIS BIAYA & DPP & Tarif \% & PPh 4 ayat 2 \\
\hline Februari & Sewa gudang & 27.215 .675 & 10 & 2.721 .567 \\
\hline & Biaya Subkontraktor & 53.974 .440 & 4 & 2.158 .977 \\
\hline
\end{tabular}




\begin{tabular}{|c|c|c|c|c|}
\hline & Biaya Subkontraktor & 45.529 .350 & 4 & 1.821 .174 \\
\hline & Biaya Subkontraktor & 141.725 .980 & 4 & 5.669 .039 \\
\hline \multicolumn{2}{|c|}{ Total Februari } & 268.445 .445 & & 12.370.757 \\
\hline \multirow[t]{6}{*}{ Maret } & Biaya Subkontraktor & 53.974 .440 & 4 & 2.158 .977 \\
\hline & Biaya Subkontraktor & 45.529 .350 & 4 & 1.821 .174 \\
\hline & Biaya Subkontraktor & 141.725 .980 & 4 & 5.669 .039 \\
\hline & Biaya Subkontraktor & 120.606 .736 & 4 & 4.824 .269 \\
\hline & Biaya Subkontraktor & 120.606 .736 & 4 & 4.824 .269 \\
\hline & Biaya Subkontraktor & 256.205 .169 & 4 & 7.686 .155 \\
\hline \multicolumn{2}{|c|}{ Total Maret } & 738.648.411 & & 26.983 .883 \\
\hline \multirow[t]{2}{*}{ April } & Biaya Subkontraktor & 142.654 .680 & 3 & 4.279 .640 \\
\hline & Biaya Subkontraktor & 195.197 .577 & 3 & 5.855 .927 \\
\hline \multicolumn{2}{|c|}{ Total April } & 337.852.257 & & 10.135.567 \\
\hline Mei & Biaya Subkontraktor & 69.391 .826 & 4 & 2.775 .673 \\
\hline \multicolumn{2}{|c|}{ Total Mei } & 69.391 .826 & & 2.775 .673 \\
\hline \multirow[t]{6}{*}{ Juni } & Biaya Subkontraktor & 46.101 .461 & 4 & 1.844 .058 \\
\hline & Biaya Subkontraktor & 118.104 .983 & 4 & 4.724 .199 \\
\hline & Biaya Subkontraktor & 37.941 .125 & 4 & 1.517 .645 \\
\hline & Biaya Subkontraktor & 100.505 .613 & 4 & 4.020 .224 \\
\hline & Biaya Subkontraktor & 44.978 .700 & 4 & 1.799 .148 \\
\hline & Biaya Subkontraktor & 142.654 .680 & 3 & 4.279 .640 \\
\hline \multicolumn{2}{|c|}{ Total Juni } & 490.286 .562 & & 18.184.914 \\
\hline \multirow[t]{2}{*}{ Juli } & Biaya Subkontraktor & 117.250 .000 & 4 & 4.690 .000 \\
\hline & Biaya Subkontraktor & 150.750 .000 & 4 & 6.030 .000 \\
\hline \multicolumn{2}{|c|}{ Total Juli } & 268.000 .000 & & 10.720 .000 \\
\hline \multirow[t]{2}{*}{ Agustus } & Biaya Subkontraktor & 59.273 .307 & 4 & 2.370 .932 \\
\hline & Biaya Subkontraktor & 195.197 .577 & 3 & 5.855 .927 \\
\hline \multicolumn{2}{|c|}{ Total Agustus } & 254.470 .884 & & 8.226 .859 \\
\hline September & Biaya Subkontraktor & 118.878 .900 & 3 & 3.566 .367 \\
\hline \multicolumn{2}{|c|}{ Total September } & 118.878 .900 & & 3.566 .367 \\
\hline \multirow[t]{6}{*}{ Oktober } & Biaya Subkontraktor & 162.644 .648 & 3 & 4.879 .339 \\
\hline & Biaya Subkontraktor & 40.202 .245 & 4 & 1.608 .089 \\
\hline & Biaya Subkontraktor & 47.241 .993 & 4 & 1.889 .679 \\
\hline & Sewa gudang & 4.720 .149 & 10 & 472.015 \\
\hline & Sewa gudang & 37.544 .000 & 10 & 3.754 .400 \\
\hline & Sewa gudang & 37.544 .000 & 10 & 3.754 .400 \\
\hline \multicolumn{2}{|c|}{ Total Oktober } & 329.897 .035 & & 16.357.922 \\
\hline \multirow[t]{3}{*}{ November } & Biaya Subkontraktor & 1.032 .010 .197 & 3 & 30.960 .306 \\
\hline & Sewa gudang & 16.250 .000 & 10 & 1.625 .000 \\
\hline & Sewa gudang & 33.670 .000 & 10 & 3.367 .000 \\
\hline \multicolumn{2}{|c|}{ Total November } & 1.081 .930 .197 & & 35.952 .306 \\
\hline \multirow[t]{2}{*}{ Desember } & Biaya Subkontraktor & 47.205 .326 & 4 & 1.888 .213 \\
\hline & Biaya Subkontraktor & 65.065 .859 & 3 & 1.951 .975 \\
\hline
\end{tabular}




\begin{tabular}{|c|c|c|c|c|}
\hline & Biaya Subkontraktor & 47.551 .560 & 3 & 1.426 .546 \\
\hline & Biaya Subkontraktor & 15.176 .450 & 4 & 607.058 \\
\hline \multicolumn{2}{|c|}{ Total Desember } & 174.999.195 & & 5.873 .792 \\
\hline
\end{tabular}

Sumber:Data diolah

PT. CAT telah melakukan kewajiban pemotongan/pemungutan $\mathrm{PPh}$ sesuai dengan Undang-undang dan ketentuan perpajakan yang berlaku. Pada tabel pemotongan objek $\mathrm{PPh}$ Pasal 4 ayat (2) seperti biaya sewa tanah/bangunan yang telah dipotong PPh sebesar $10 \%$ sesuai dengan PP No. 34 tahun 2017 yang mengatur tentang PPh dari Penghasilan Pesewaan Tanah dan/atau Bangunan. Dalam menjalankan proyeknya PT.CAT menggunakan beberapa jasa subkontraktor, bagi subkontraktor yang memiliki kualifikasi usaha dikenakan PPh sebesar 3\%, kemudian bagi yang tidak memiliki kualifikasi usaha dikenakan PPh sebesar $4 \%$ sesuai dengan Peraturan Pemerintah Nomor 40 tahun 2009 tentang Perubahan atas Peraturan Pemerintah Nomor 51 tahun 2008 tentang Perpajakan Jasa Konstruksi.

\section{SIMPULAN}

Berdasarkan dari penelitian yang dilakukan terhadap penerapan tax planning atas withholding tax terhadap PPh Badan pada PT. CAT 2018, maka dapat diambil kesimpulan sebagai berikut:

1. Penerapan tax planning yang dilakukan PT. CAT pada objek PPh Pasal 21 belum dilakukan secara optimal, perusahaan melakukan perhitungan PPh Pasal 21 dengan metode gross up yang menghasilkan PPh Pasal 21 terutang sebesar Rp. 338.184.033, sedangkan dalam penelitian penulis melakukan perhitungan dengan metode nett dan menghasilkan PPh Pasal 21 terutang sebesar Rp. 284.922.159. Dari penelitian yang dilakukan menghasilkan penghematan pajak sebesar Rp. 53.261.874 (Rp. 338.184.033 - 284.922.159), sehingga perusahaan dinilai melakukan inefisiensi terhadap beban pajak yang dibayarkan.

2. Pelaksanaan tax planning atas withholding tax yang dilakukan PT. CAT tehadap objek PPh Pasal 22 Impor telah dilakukan sesuai dengan ketentuan pajak yang berlaku guna menghindari SPT Tahunan lebih bayar karena kredit pajak PPh Pasal 22 Impor dan inefisiensi terhadap beban pajak terutang.

3. Pelaksanaan tax planning atas withholding tax PPh Pasal 23 dan Pasal 4 ayat (2) telah dilakukan dengan baik sesuai dengan ketentuan perpajakan yang berlaku dan tidak ditemukan potensi pajak kurang bayar yang masih harus dipotong atau dipungut untuk tahun 2018.

4. Dengan membandingkan pengunaan metode net dan metode gross up dalam melakukan perhitungan PPh Pasal 21 terutang, ditemukan selisih beban pajak sebesar Rp. 53.261.874 (Rp. 338.184.033 - 284.922.159). Hal ini menjadikan penggunaan metode net lebih menguntungkan daripada metode gross up, untuk jenis perusahaan yang dikenakan pajak bersifat final.

\section{DAFTAR PUSTAKA}

Agus, S. 2014. Auditing Petunjuk Praktis Pemeriksaan Akuntan oleh Akuntan Publik . Edisi ke 4. Jakarta: Salemba Empat.

Anwar Pohan, C. 2018. Manajemen Perpajakan. Jakarta: PT. Gramedia Pustaka Utama.

Arifin, M. Z., Syafi'i, \& Pudjowati, J. 2017. Penerapan Tax Planning Pada Perusahaan Jasa Konstruksi Pada CV. AK Karya Surabaya. Jurnal Ekonomi Akuntansi Vol. 3, 78-93.

Ayuningsih, S. R. 2016. Penerapan Tax Review Atas Pajak Penghasilan Badan dan Witholding Tax Pada PT. ABC. E-Jurnal Akuntansi Universitas Udayana, 1-27.

Direktorat Jenderal Pajak. Undang-undang Nomor 16 Tahun 2009 tentang Ketentuan Umum dan Tata Cata Perpajakan.

Direktorat Jenderal Pajak. Undang-undang Nomor 36 tentang Pajak Penghasilan.

Kasmir. 2016. Analisis Laporan Keuangan. Jakarta: PT Raja Grafindo Persada. 
Kondoy, V., Nangoi, G., \& Elim, I. 2016. Analsis Penerapan Pajak Penghasilan Konstruksi Pada CV. Cakrawala. Jurnal Berkala Ilmiah Efisiensi, Vol. 16 No. 4, 169-180.

Mardiasmo. 2016. Perpajakan Edisi Revisi 2016. Yogyakarta: Andi. 2018. Perpajakan Edisi Revisi 2018. Yogyakarta: Andi.

Mukhtar. 2013. Metode Praktis Penelitian Deskriptif Kulitatif. Jakarta: GP Press Group.

Rani, R. Jenis Tarif Pajak. diakses 14 April 2018, dari http://www.online-pajak.com

Republik Indonesia. Peraturan Menteri Keuangan Nomor 141/PMK.03/2015 Tentang Jenis Jasa Lainnya Yang Dikenakan PPh Pasal 23.

Republik Indonesia. Undang-undang No. 18 Tentang Jasa Konstruksi Tahun 1999.

Republik Indonesia. Peraturan Pemerintah Nomor 28 Tahun 2000 Tentang Usaha dan Peran Masyarakat Jasa Konstruksi.

Republik Indonesia. Peraturan Menteri Pekerjaan Umum No.04/PRT/M/2011 tentang Pedoman Persyaratan Pemberian Izin Usaha Jasa Konstruksi.

Republik Indonesia. Peraturan Pemerintah Nomor 34 Tahun 2017 Tentang Pajak Penghasilan Atas Pernghasilan Dari Persewaan Tanah dan/atau Bangunan.

Republik Indonesia. Peraturan Pemerintah Nomor 51 Tahun 2008 sebagaimana telah diubah terakhir dengan Peraturan Pemerintah Nomor 40 Tahun 2009 Pajak Penghasilan Usaha Jasa Konstruksi.

Resmi, S. 2014. Perpajakan, Teori dan Kasus Edisi 8. Jakarta: Salemba Empat.

Septriadi, D. d.. Perlunya Pembatasan Sistem Withholding Tax atas Penghasilan Usaha dalam RUU PPh. 09 Januari 2008. diakses 15 Juni 2019, dari https://www.ortax.org

Sugiyono. 2017. Metode Penelitian Kuantitatif, kualitatif dan R\&D. Bandung: CV Alfabeta.

Waluyo. 2019. Akuntansi Pajak . Edisi 6. Jakarta: Salemba Empat.

Weygandt, K. a. 2013. Financial Accounting: IFRS Edition. Hoboken: John Wiley \& Sons, Inc. www.pajak.go.id. Aspek Perpajakan Jasa Konstruksi. 